http://ejournal.upi.edu/index.php/jaz - e-mail: jurnal.zonasi@gmail.com dan jurnal_zonasi@upi.edu doi.org/10.17509/jaz.v3i3.27050

\title{
KONSEP INTEGRASI STASIUN LRT BEKASI TIMUR DENGAN KAWASAN MIXED-USE LRT CITY BEKASI TIMUR
}

Article History:
First draft received:
5 Agustus 2020
Revised:
29 Agustus 2020
Accepted:
8 September 2020
Final proof received:
Print:
15 Oktober 2020

Online
20 Oktober 2020

Jurnal Arsitektur ZONASI
is indexed and listed in
several databases:
SINTA 4 (Arjuna)
GARUDA (Garda Rujkan Digital)
Google Scholar
Dimensions
oneSearch
BASE
Member:
Crossref
RJI
APTARI
FJA (Forum Jurna Arsitektur)
IAI
AJPKM

Indira Nur Anissa ${ }^{1}$ Agus Saladin ${ }^{2}$ Nuzuliar Rahmah ${ }^{3}$

1, Mahasiswi Jurusan Arsitektur, FTSP, Universitas Trisakti

2,3 Dosen Jurusan Arsitektur, FTSP, Universitas Trisakti, Jakarta

Jl. Kyai Tapa No.1, RT.6/RW.16, Grogol, Kec. Grogol petamburan, Kota Jakarta Barat, Daerah Khusus Ibukota Jakarta 11440

Email: 1indira052001600030@std.trisakti.ac.id 2agus.saladin@trisakti.ac.id ${ }^{3}$ nuzuliar@trisakti.ac.id

Abstract: The mixed-use area which is located outside Jakarta (satellite city) can be an alternative for the people of DKI to settle or to do activities so that the density of Jakarta can decline. Areas with various functions such as residential, office and trade can be held well if the inter-building can be well integrated and can provide mobility and accessibility is good for the region users to get to the center of Jakarta. The purpose of this writing is to know and analyze the concept of integration between the mixed-use LRT City Bekasi Timur area with East Bekasi LRT station. The research was conducted by the method of planning approach by developing a situation with creativity and producing a solution in the form of design work. Based on the results of the analysis, the concept of integration between East Bekasi LRT station with the Mixed-use LRT City area is through a connecting Jembatann, considering that the station is located 20 meters from the ground level. The bridge connects the station to the surrounding buildings especially in the commercial area and office area, which is the building Lifestyle Mall, office and Park $n$ Ride. The connecting bridge is designed for people with disabilities and protects the user from heat and rain because it is closed at the top but can still see the surrounding area on its left-right.

Keywords: Complex, Mixed-use Complex, Integration.

Abstrak: Kawasan mixed-use yang berada diluar Jakarta (kota satelit) dapat menjadi alternatif bagi penduduk DKI untuk menetap atau melakukan kegiatan sehingga kepadatan kota Jakarta dapat menurun. Kawasan dengan berbagai fungsi didalamnya seperti hunian, perkantoran dan perdagangan dapat berlangsung dengan baik apabila antar bangunannya dapat terintegrasi dengan baik dan dapat memberikan mobillitas dan aksesibilitas yang baik bagi pengguna kawasan untuk menuju pusat kota Jakarta. Tujuan dari dibuatnya penulisan ini untuk mengetahui serta menganalisa konsep integrasi antara kawasan mixed-use LRT City Bekasi Timur dengan stasiun LRT Bekasi Timur. Penelitian dilakukan dengan metode pendekatan perancangan dengan mengembangkan suatu situasi dengan kreatifitas dan menghasilkan suatu penyelesaian berupa karya perancangan. Berdasarlan hasil analisis, konsep integrasi antara stasiun LRT Bekasi Timur dengan kawasan Mixed-use LRT City adalah melalui jembatann penghubung, karena mempertimbangkan letak stasiun yang berada 20 meter dari permukaan tanah. Jembatan menghubungkan stasiun dengan bangunan sekitar khususnya pada area komersial dan area perkantoran, yaitu bangunan Lifestyle mall, Kantor dan park $n$ ride. Jembatan penghubung didesain ramah bagi penyandang disabilitas dan melindungi pengguna dari panas dan hujan karena tertutup pada bagian atas tetapi tetap dapat melihat kesekitar kawasan pada bagian kanan kirinya.

Kata Kunci: Kawasan, Kawasan Mixed-use, Integrasi. 


\section{Pendahuluan}

DKI Jakarta sebagai sebuah ibukota dengan jumlah penduduk yang mencapai 10,6 juta jiwa (BPS 2019) dan memiliki luas wilayah $664,02 \mathrm{~km}^{2}$ memiliki beberapa permasalahan. Salah satu permasalahan provinsi DKI Jakarta sebagai ibukota adalah kepadatan penduduk. Menurut Badan Pusat Statistik DKI Jakarta, tingkat pertumbuhan penduduk Jakarta terus bertambah menacapai 98 ribu jiwa per tahunnya.. Salah satu solusi dari kepadatan penduduk DKI Jakarta yang terus naik adalah dengan cara menciptakan kawasan baru diluar DKI Jakarta dengan tingkat mobilitas dan aksesibilitas yang mudah menuju kota Jakarta. Dengan dibuatnya kawasan Mixed-use di kota satelit Jakarta (dalam hal ini Bekasi Timur) bisa membuat penduduk menetap, bekerja dan rekreasi di tempat yang sama dengan tetap memilliiki mobilitas yang mudah untuk penduduk yang harus melakukan kegiatan di Jakarta.

Mixed-use merupakan penggunaan campuran berbagai tata guna lahan atau fungsi dalam bangunan (Procos 1976). Kawasan Mixed-use merupakan suatu wilayah atau daerah yang memiliki ciri tertentu dengan memiliki beberapa fungsi kegiatan antara lain hunian, perkantoran dan komersial/rekreasi.

Dengan adanya banyak fungsi dalam kawasan, perlu adanya konektivitas yang baik sehingga kegiatan dan mobilitas dalam kawasan dapat dengan mudah dilakukan sehingga setiap fungsi bangunan tidak "bekerja sendiri" dan dapat menghilangkan sebuah kesatuan dalam kawasan. Perlu juga adanya interaksi sosial yang baik dalam keberlangsungan suatu kawasan sehingga terciptanya kawasan yang hidup. Konektivitas pada sebuah kawasan terdapat diantara fungsi bangunan maupun antara bangunan dengan transportasi penunjang aksesibilitas kawasan. Seperti halnya dalam kriteria TOD, perlu adanya integrasi atau konektivitas yang baik dalam suatu kawasan TOD (Tiara, Ikaputra, and Widyastuti 2017). Konektivitas antara stasiun LRT sebagai penghubung mobilitas jarak jauh dengan kawasan perlu adanya penghubung atau konektivitas yang baik yang juga dapat berperan sebagai transisi antara kawasan dengan luar kawasan sehingga konektivitas atau integrasi antara stasiun dengan kawasan perlu direncanakan dengan baik. Pendekatan yang tepat dalam ini yang dibahas merupaka integrasi moda dengan kawasan. Integrasi Moda dengan kawasan sudah banyak dilakukan khususnya antara stasiun baik LRT ataupun KRL, dengan ini referensi khususnya di ibukota Jakarta cukup banyak dan bukan lagi sebuah hal baru.

Stasiun LRT cukup membawa dampak besar dalam perpindahan keluar-masuk pengunjung ataupun penghuni kawasan dikarenakan letaknya yang berdampingan berada di sisi kawasan. Pengguna LRT memiliki tujuan yang pasti berbeda satu dan lainnya, terdapat pengguna LRT yang memang bertujuan mengunjungi kawasan, terdapat pengguna yang bertujuan untuk pulang karena merupakan penghuni kawasan dan terdapat juga pengguna LRT yang hanya melakukan transit yang kemudian meneruskan perjalanannya ketempat lain. Sehingga aksesibilitas dan konektivitas antara stasiun dan kawasan perlu diperhatikan dikarenakan akses penumpang LRT hanya melalui kawasan. Sehingga dibutuhkannya integrasi antar moda dan kawasan yang nyaman juga efisien dalam penggunaannya, baik pengguna yang akan mengunjungi kawasan maupun hanya transit untuk kemudian berpindah ke tempat lain.

Kawasan Mixed-use merupakan suatu kawasan multifungsi yang berisi bermacam kegiatan yang berbeda dan saling melengkapi satu sama lainnya serta saling berinteraksi (ULI 1985). Pada dasarnya, kawasan Mixed-use merupakan suatu kawasan yang dirancang teritegrasi dengan kepadatan bangunan yang cukup tinggi dengan beragam fungsi bangunan(Fadhilah et al. 2018). Kawasan Mixed-use juga harus menjadi kawasan yang mandiri, maksudnya adalah kawasan dimana penghuninya dapat tinggal, bekerja dan berekreasi di dalam kawasan tersebut.

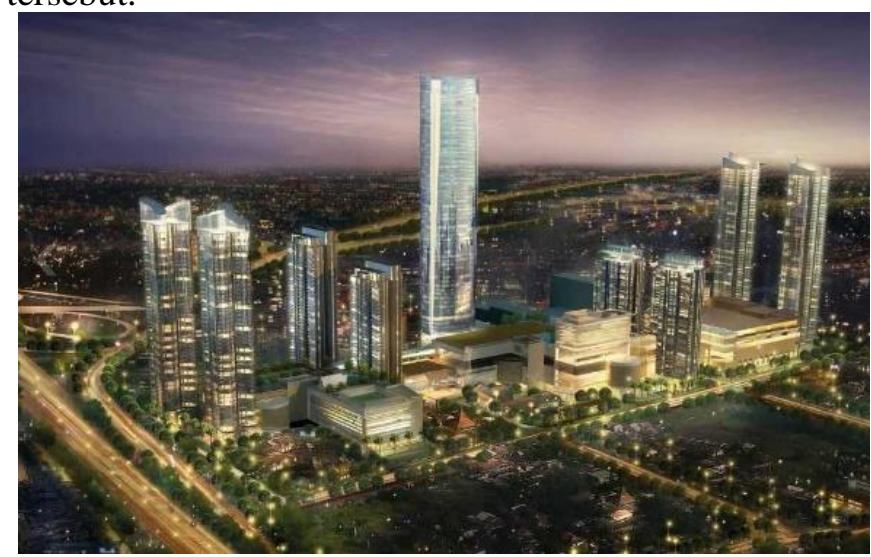

Gambar 1. Contoh gambar kawasan Mixed-use

Sumber : Alfari 2017 
Perancangan kawasan berfungsi campuran bertujuan juga untuk mengurangi kemacetan dengan meminimalkan pergerakan manusia sehingga tidak perlu keluar kawasan untuk melakukan kegiatan (Tondobala 2012). Dalam perkembangan selanjutnya, atas dasar kebutuhan mencapai efisiensi berbagai komponen perkotaan, maka konsep integrasi perlu mengakomodasi persyaratan untuk mewujudkan keserasian dan keterpaduan dalam penataan ruang demi mencapai pembanguna yang berkelanjutan (Wibisono 2010). Dalam hal ini, kawasan mixed-use dirancang juga sebagai area transit bagi pengguna LRT.

Secara umum, Integrasi memiliki arti sebuah pembauran sehingga menjadi suatu kesatuan. Integrasi jaringan merupakan salah satu kesuksesan sistem pelayanan transportasi publik (Neumann, Nagel 2011) dikarenakan dengan terintegrasinya sistem jaringan transportasi publik, rute jaringan terbaik dapat juga ditentukan melalui mekanisme jangkauan pelayanan yang optimal, bukan hanya berdasarkan permintaan kebutuhan perjalanan masyarakat (Murray 2001). Dalam bukunya, (Ching 2003) menyatakan suatu susunan yang harmonis dapat tercipta dengan menata dimana tiap bagiannya dari sisi arsitekturalnya saling berhubungan. Prinsip dasar penataan antara lain: sumbu, simetri, hierarki, datum, irama, dan transformasi.

Integrasi Transportasi publik dengan bangunan sekitar dibutuhkan agar pencapaian penguna dapat terfasilitasi dan mudah di akses oleh siapapun (Rosada, Purnomo, and Rahma 2017). Hal ini juga dapat mempersingkat mobilitas pengguna kawasan maupun pengguna LRT.

\section{Metode Penelitian}

Metode yang digunakan dalam penelitian ini adalah pendekatan perancangan untuk memecahkan suatu masalah dalam perancangan (Bagaskara et al. 2019) . Metode ini dilakukan untuk mengembangkan suatu situasi dengan kreatifitas dalam menghasilkan suatu penyelesaian berupa karya perancangan. Pendekatan perancangan dilakukan meliputi:

1. Pendakatan Tipologi pada perancangan yaitu bentuk integrasi antara transportasi massal dengan bangunan sekitar.

2. Pendekatan Tematik pada kawasan ini adalah kawasan berbasis Transit Oriented Development (TOD) yang terintegrasi dengan transportasi massal yaitu stasiun LRT.

3. Pendekatan lokasi dan tapak dilakukan analisis terhadap lokasi perancangan maupun lingkungan sekitar tapak.

\section{Hasil dan Pembahasan}

LRT City Bekasi Timur terletak di samping toll Jakarta - Cikampek dengan luas area yang dibangun pada tahap 1 seluas $73.980 \mathrm{~m}^{2}$ yang berbatasan dengan Kali Malang dan Jl. HM. Joyo Martono. Menurut Perda Kota Bekasi No. 05 Tahun 2016 tentang Rencana Detail Tata Ruang, lahan ini diperuntukan untuk fungsi campuran serta memliki KDB sebesar $40 \%$ dengan tinggi maksimal sesuai dengan Ketentuan Kawasan Keselamatan Operasi Penerbangan yaitu 100 meter.

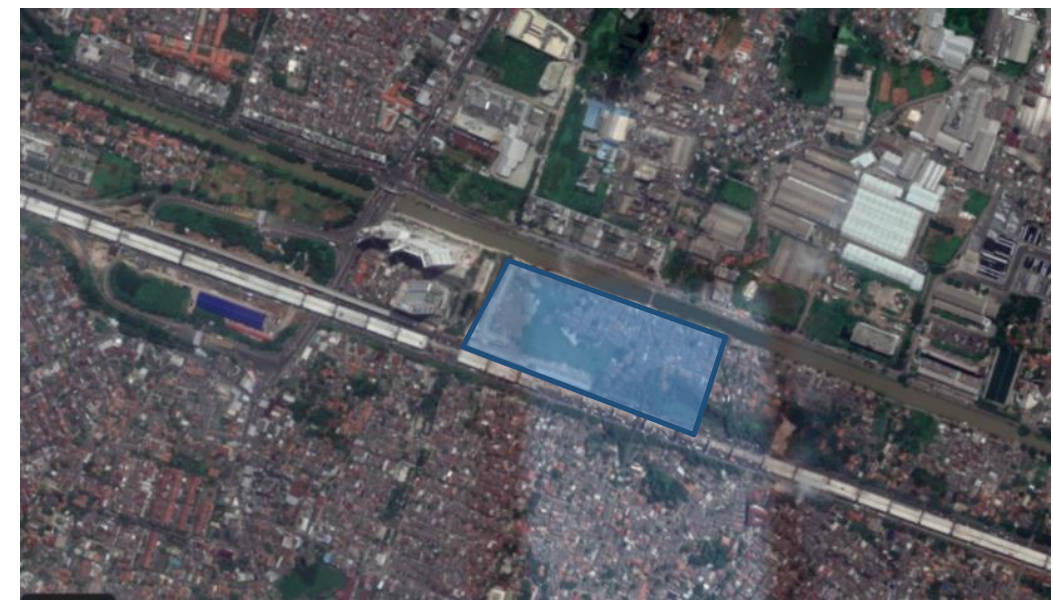

Gambar 2. Lokasi Tapak

Sumber : Analisis, 2020 
Kawasan ini terdiri dari beberapa fungsi bangunan, antara lain Hunian (Apartemen), Komersial (Mall dan Retail) dan Kantor. Terdapat pula Park and Ride untuk menunjang pengguna LRT dan plaza sebagai ruang terbuka untuk menghubungkan area komersial.

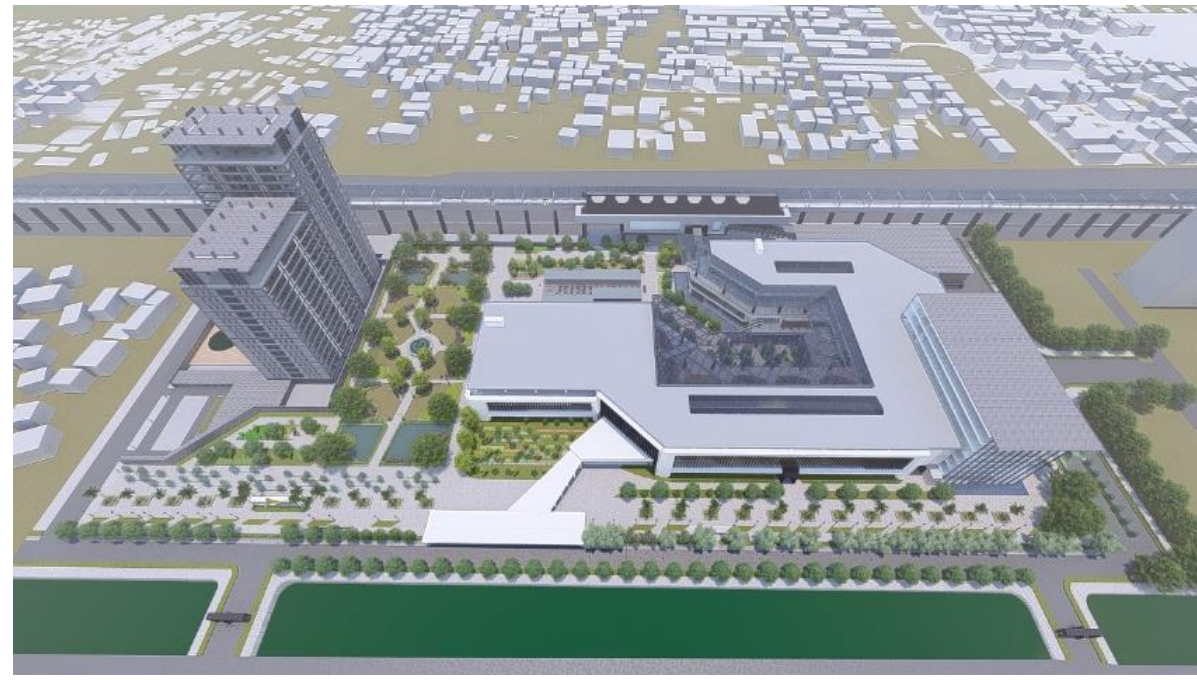

Gambar 3. Perspektif Kawasan

Sumber : Analisis 2020

Berlatar belakang kondisi kemacetan di daerah Jakarta dan sekitarnya, pemerintah membangun LRT untuk menunjang perpindahan masyarakat khususnya area jabodetabek. Salah satu stasiun LRT terdapat di Bekasi Timur yang juga merupakan stasiun terakhir untuk rute Cawang - Jatimulya.

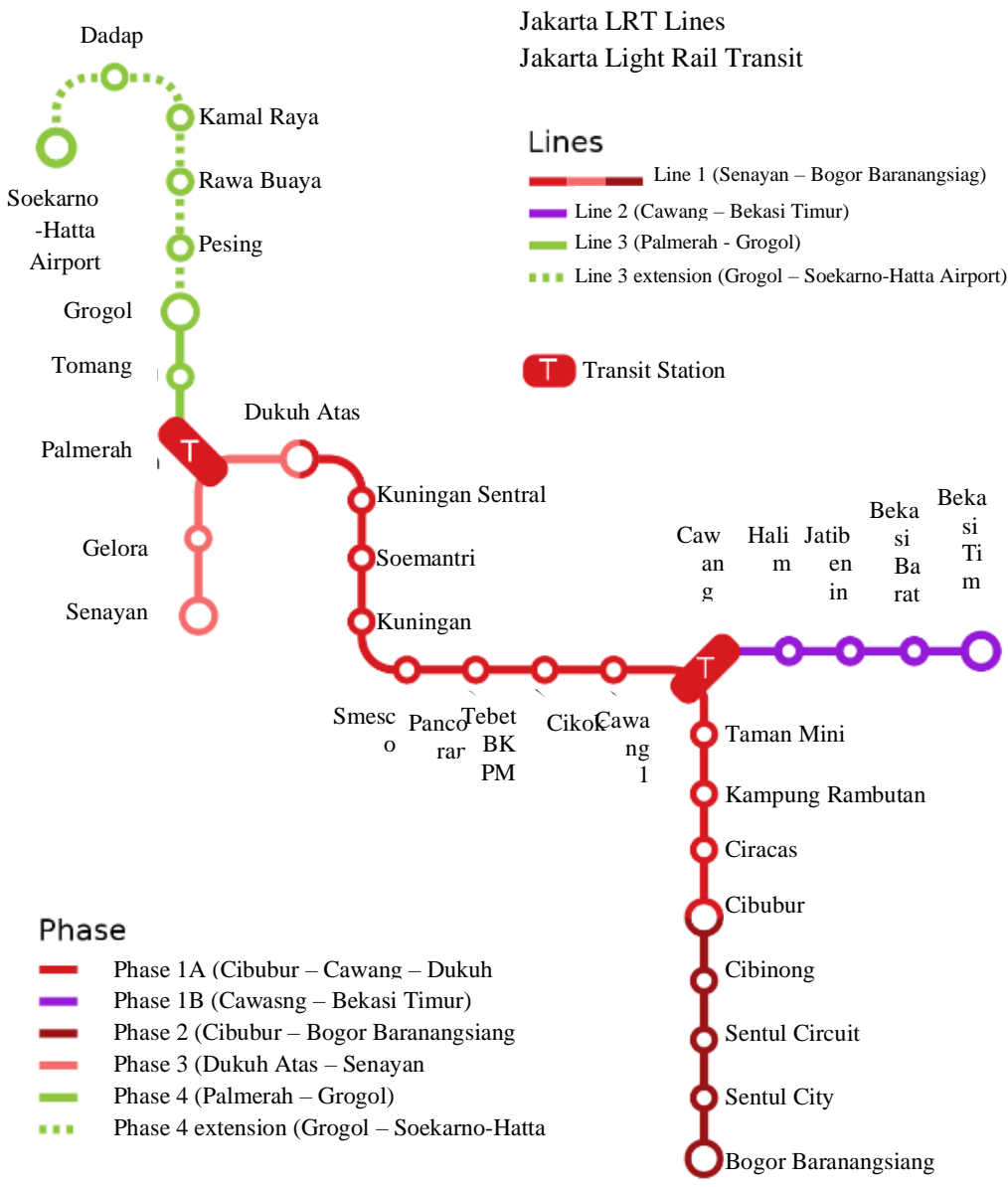

Gambar 4. Rute LRT

Sumber : Google Image 
Pengguna stasiun pun memiliki tujuan yang berbeda, atu dan lainnya, terdapat pengguna LRT yang memang bertujuan mengunjungi kawasan, terdapat pengguna yang bertujuan untuk pulang karena merupakan penghuni kawasan dan terdapat juga pengguna LRT yang hanya melakukan transit yang kemudian meneruskan perjalanannya ketempat lain. Dalam menciptakan kemudahan aksesibilitas menuju kawasan Mixed-use dari stasiun LRT maupun sebagai area transisi dari stasiun (luar kawasan) dan area kawasan mixed-use perlu adanya integrasi yang baik. Kawasan mixed-use terdiri berbagai fungsi bangunan sehingga integrasi dari stasiun harus semaksimal mungkin menjangkau tiap fungsi bangunan khususnya yang bersifat publik. Fungsi bangunan pada kawasan yang berada dekat dengan stasiun adalah Lifestyle Mall, Office dan Park and Ride. Dalam hal ini, stasiun memiliki integrasi dengan ketiga bangunan tersebut.

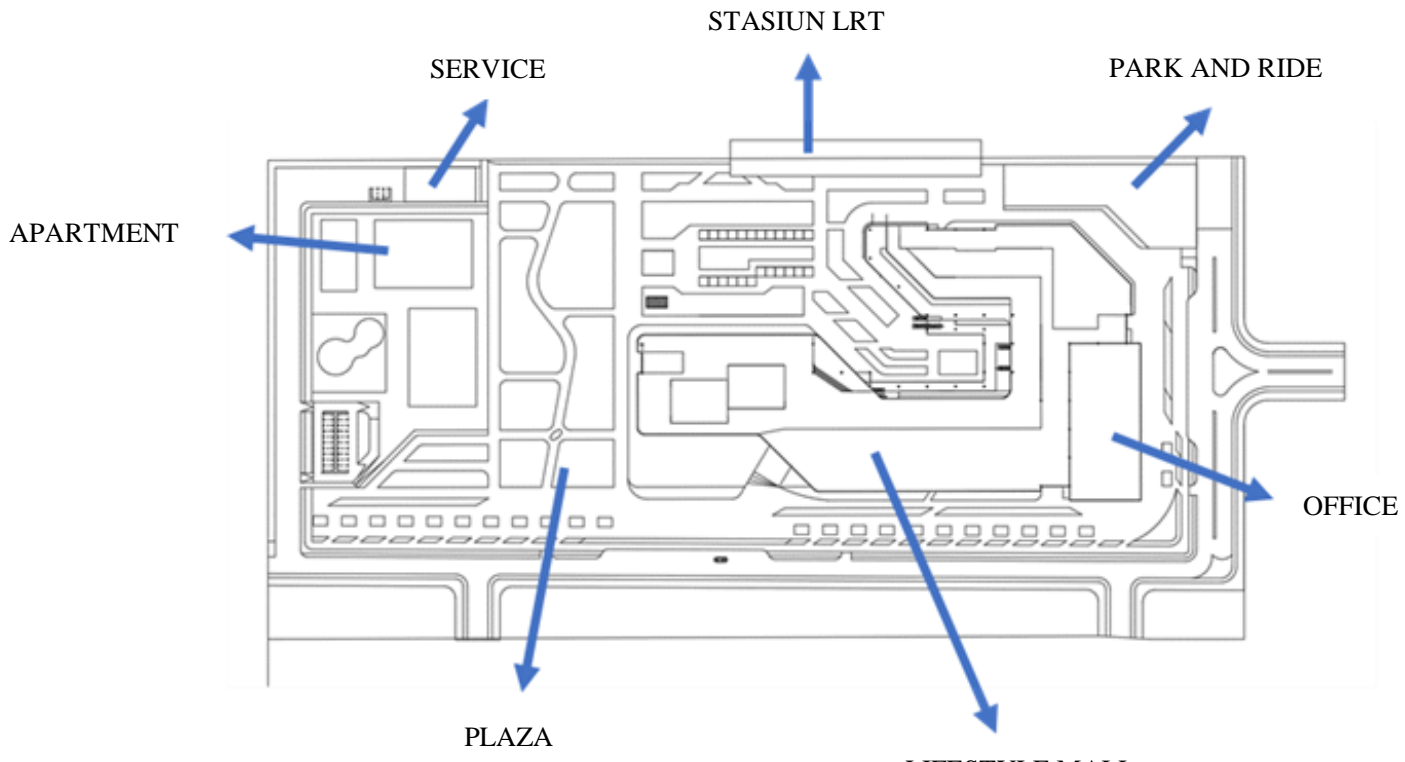

LIFESTYLE MALL

Gambar 5. Fungsi massa bangunan

Sumber : Analisis, 2020

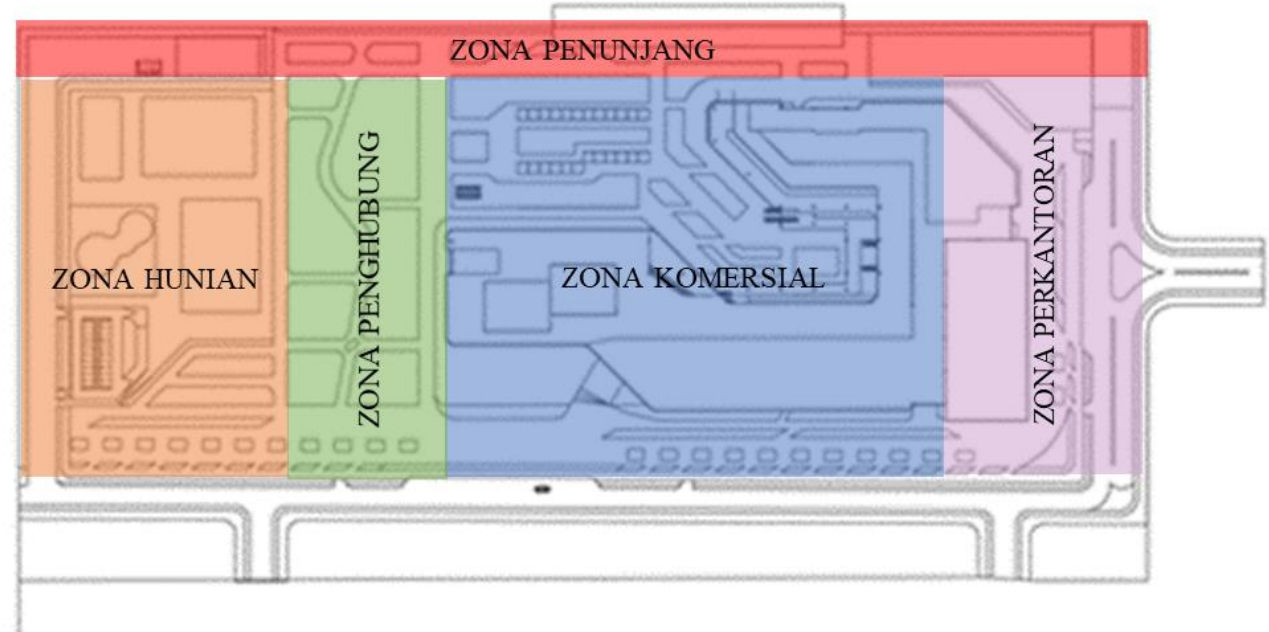

Gambar 6. Zonasi Kawasan

Sumber : Analisis, 2020

Posisi stasiun berada tepat disisi jalan Toll dan kawasan dengan ketinggian 20 meter diatas permukaan tanah. Dengan mempertimbangkan hal tersebut integrasi langsung menuju plaza sulit dilakukan. Integrasi langsung hanya berupa lift untuk membantu pengguna difabel agar mudah mengakses stasiun. Sehingga integrasi yang digunakan adalah melalui bangunan sekitar stasiun. Integrasi yang digunakan antara stasiun dengan kawasan ini adalah jembatan penghubung. 


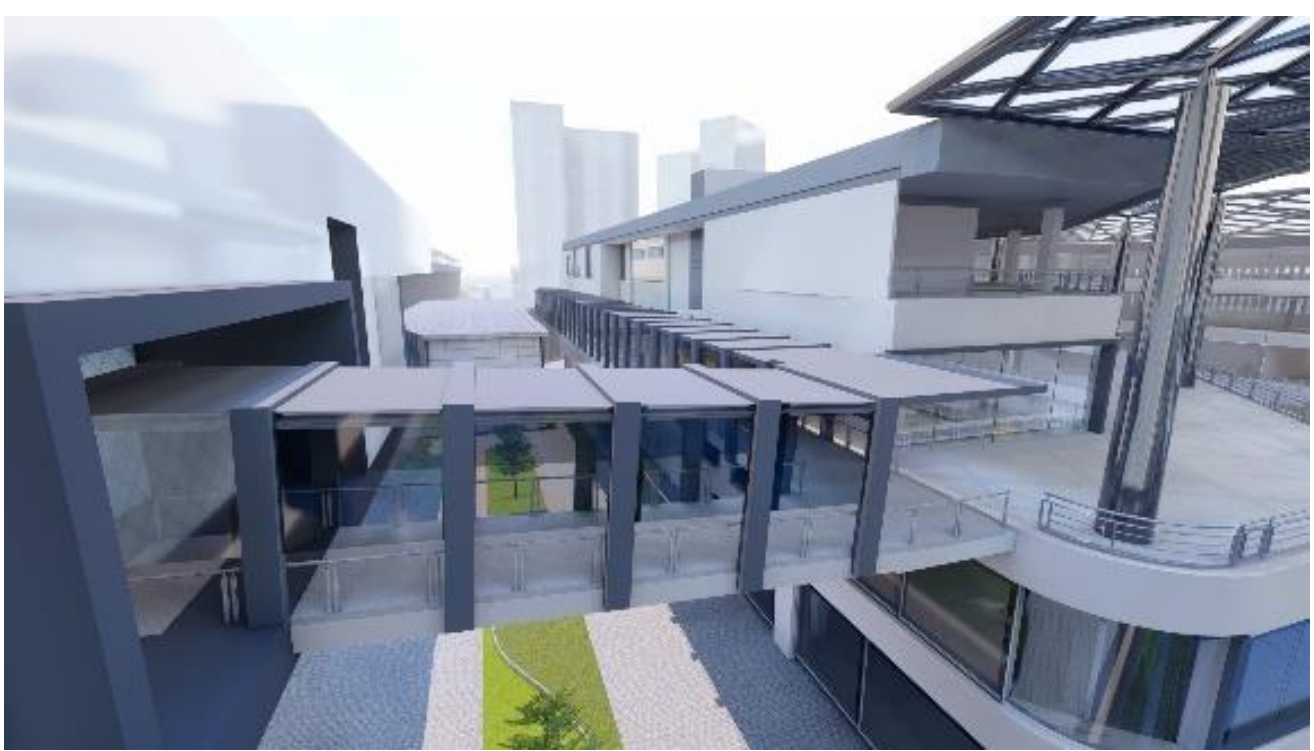

Gambar 7. Jembatan Penghubung

Sumber : Analisis, 2020

Terdapat 2 akses jembatan untuk keluar dari stasiun, jembatan pertama memiliki akses langsung ke bangunan park $n$ ride, sedangkan jembatan lain menghubungkan stasiun dengan mall dan office. Untuk bangunan apartment tidak memiliki akses langsung berupa jembatan menuju stasiun LRT dikarena apartemen bersifat privat sehingga akses menuju apartemen dibatasi.

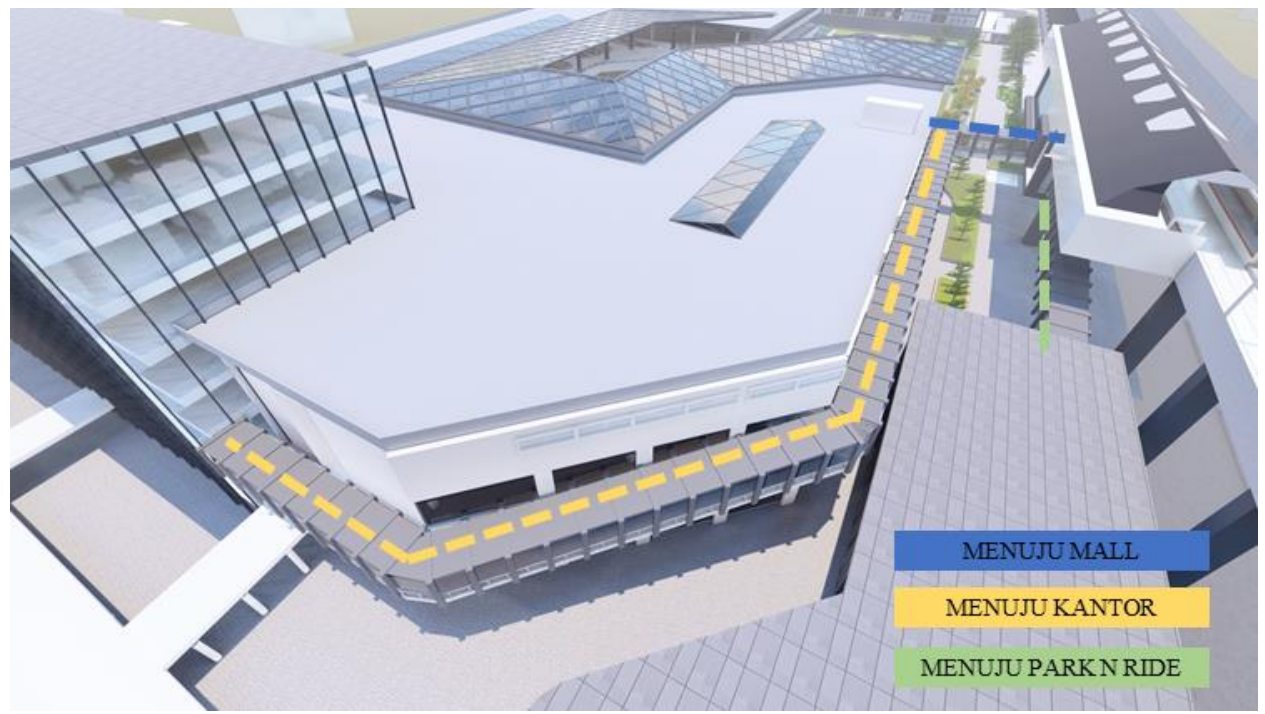

Gambar 8. Alur Jembatan Penghubung

Sumber : Analisis, 2017

Jembatan sebagai penghubung dari stasiun LRT dengan kawasan dibuat landai dengan ramp sehingga nyaman bagi pejalan kaki maupun penyandang disabilitas. Dengan penutup atap sehingga pengguna aman dari hujan dan panas serta sisi kanan dan kirinya terdapat kaca pelindung diatas railing dengan tujuan pengguna dapat tetap melihat ke sekitar dengan tetap terlindung dari cuaca. 


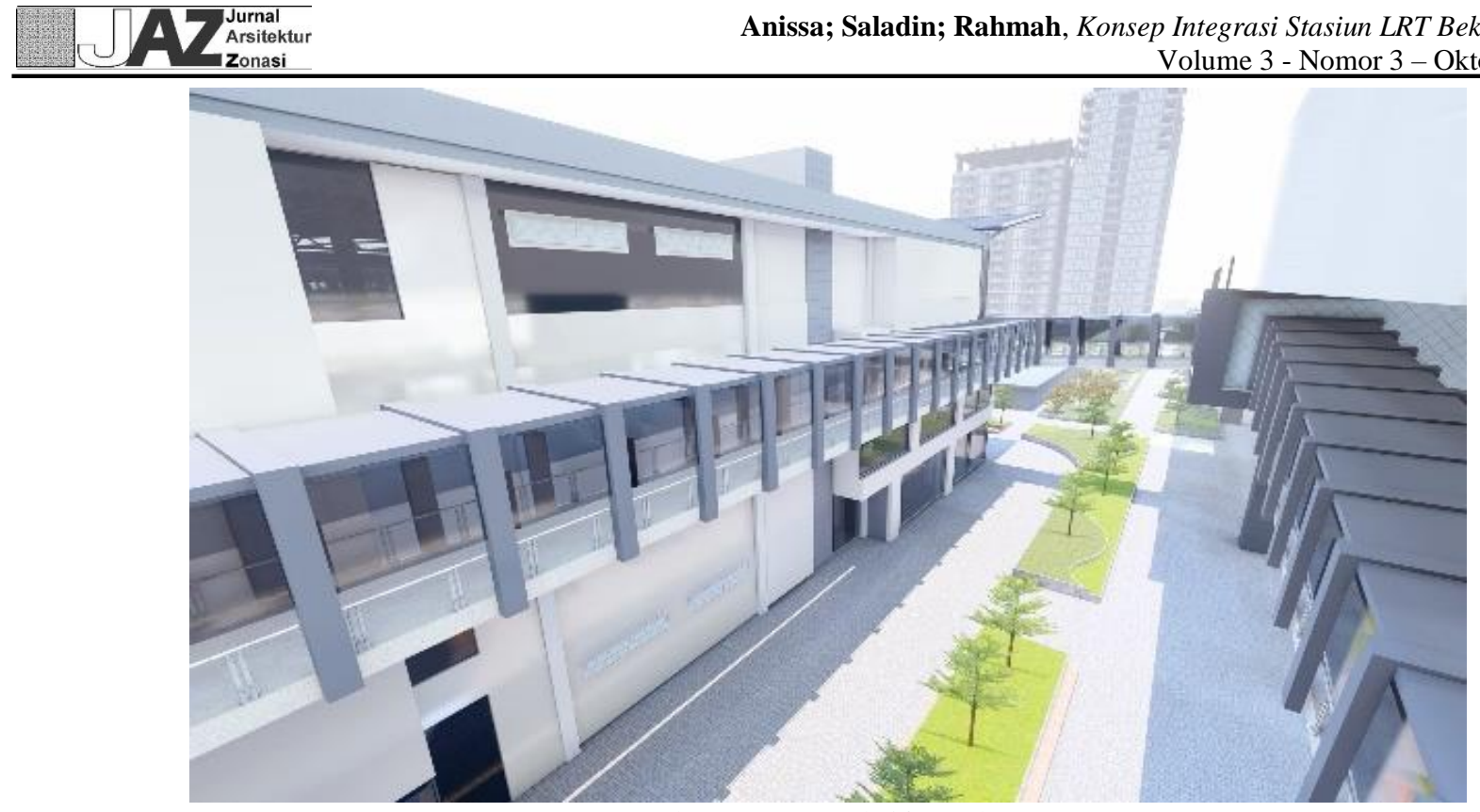

Gambar 9. Perspektif Jembatan

Sumber : Analisa, 2020

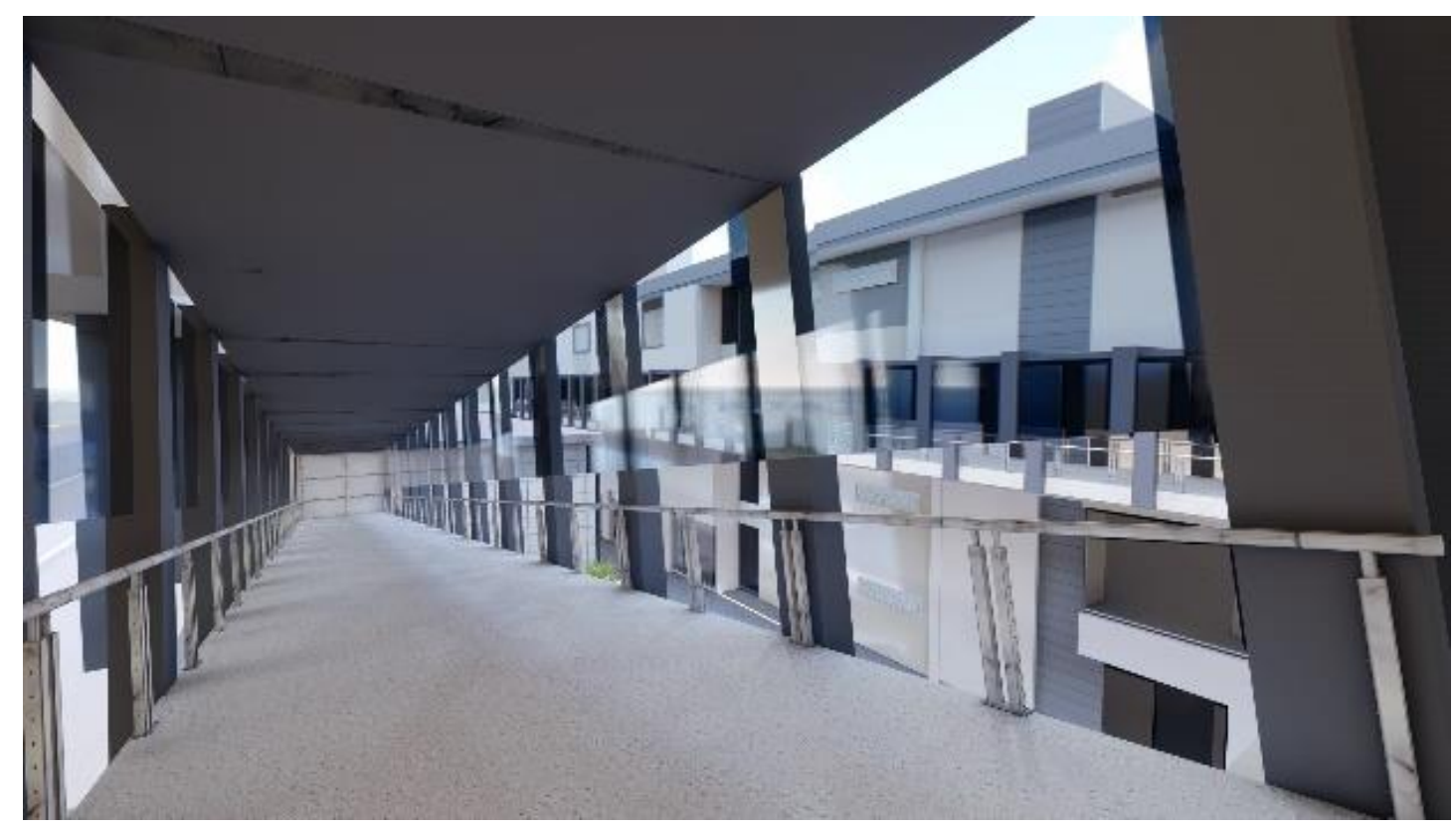

Gambar 10. Perspektif bagian dalam jembatan

Sumber : Analisa, 2020

\section{Kesimpulan}

Hasil dari penelitian menunjukkan bahwa konsep integrasi yang diterapkan pada kawasan mixed-use berbasis Transit Oriented Development (TOD) di Bekasi Timur berupa jembatan penghubung dikarenakan posisi stasiun yang berada 20 meter diatas permukaan tanah sehingga integrasi dari stasiun menuju bangunan sekitar menggunakan jembatan penghubung.

Jembatan menghubungkan stasiun dengan area komersil dan perkantoran (lifestyle mall dan kantor). Hubungan antara staisun dengan bangunan hunian (apartemen) hanya melewati plaza yang kemudian terhubung menuju area hunian.

Jembatan penghubung dibuat nyaman bagi seluruh pengguna sehingga semua dapat menggunakan fasilitas tersebut dan tentunya aman dari cuaca panas maupun dingin karena jembatan tertup dengan tetap melihat kondisi kawasan melalui sisi kanan dan kiri jembatan. 


\section{Referensi}

Alfari, Shabrina. (2017). Kawasan MixUsed. Arsitag Website. from https://www.arsitag.com/article/ kawasan-mix-used

Bagaskara, Dandi Faizal, Agus Saladin, Moh Ali Topan, Mahasiswa Program, Studi Arsitektur, Universitas Trisakti, Dosen Jurusan Arsitektur, and Universitas Trisakti. 2019. "THE APPLICATION OF FUTURISTIC IMAGERY IN THE DESIGN OF CONVENTION AND EXHIBITION BUILDINGS IN SURAKARTA." Seminar Intelektual Muda 1-4.

BPS, DKI. 2019. "Badan Pusat Statistik DKI Jakarta." (1):6-8.

Ching, Francis D. K. 2003. Arsitektur Bentuk, Ruang Dan Tatanan.

Fadhilah, Muthiah, Enny Supriyati Sardiyarso, Julindiani Iskandar, and Maria Immaculata. 2018. "KOMPARASI KONSEP INTEGRASI FUNGSI PADA BANGUNAN MIXED-USE." Seminar Nasional Cendekiawan Ke 4 Tahun 2018 515-20.

Murray, Alan T. 2001. "Strategic Analysis of Public Transport Coverage." Socio-Economic Planning Sciences 35(3): 175-88.

Neumann. A, Nagel. K. 2011, A paratransit-inspired evolutionary process for public transit network design, Annual Meeting Preprint-Ähnliche Artikel-Alle 4 Versionen, Berlin.

Procos, Dimitri. 1976. Mixed Land Use from Revival Too Innovation. Dowdin Hutchinson \& Ross. Inc. Pennsylvania.

Rosada, Rintisdayati Anindita, Agus Budi Purnomo, and Nuzuliar Rahma. 2017. "Integrasi Antar-Moda Pada Stasiun Universitas Indonesia Di Depok Inter-Modal Integration At University of Indonesia Railway Station in Depok." Seminar Nasional Cendekiawan Ke 3 Tahun 2017 173-82.

Tiara, Okita Sisy, Ikaputra, and Dyah Titisari Widyastuti. 2017. "Konektivitas Intermoda Pada Pengembangan Stasiun Manggarai Yang Berbasis Transit Oriented Development." 89-100.

Tondobala, Linda. 2015. "Pengembangan Struktur Ruang: Mereduksi Mobilitas Perkotaan". Media Matrasain. 12 (2). 73-79.

ULI. 1985. Office Development Hand Book. The Urban Land Institude.

Wibisono, Bambang Hari. 2010. Superblock: Solusi Atau Masalah Baru Bagi Perkembangan Perkotaan Di Indonesia 